

\title{
Design and Art Guidelines for Complex Structures
}

\author{
Bujar Bajçinovci ${ }^{*}$ \\ ${ }^{1}$ University of Prishtina, "UP”, Faculty of Civil Engineering and Architecture, Kosovo. \\ "Email: bujar.bajcinovci@uni-pr.edu
}

\begin{abstract}
Drawn words are better recalled than written! Furthermore, pictures are better remembered than items studied as words even when test items are presented as words, clearly, and evidently presented in many conducted research tests. The picture superiority effect showed a clear developmental trend. Designing commercial buildings poses urban and compositional challenges, especially when the production process implies the use of various technological equipment that can pollute the environment. In general, Kosovo's industrial development was based on the exploitation of raw materials and their processing to a certain degree, but not to a satisfactory degree of processing and finalization. Diversity of design of complex structures must always be in line with the requirements of technological processes, trends, economic development, environmental protection and sustainable human development. The study presented in this paper investigated the visual design guidelines for complex structures, focusing on architectural design issues, aimed primary for education purposes. The research method consists of empirical observation through the Prishtina region zone, with an accent to the urban shapes, design functionality, visual perception, and compositional harmony as a contemporary reflection to the design system models. Furthermore, the conceptual instructions from this research, show the need and necessity of adopting the visual design guidelines as the superiority teaching method.
\end{abstract}

Keywords: Design Architecture, Art, Complex Structures, Education, Guidelines 


\section{INTRODUCTION}

"Drawn words are better recalled than written" [1]! Furthermore, "pictures are better remembered than items studied as words even when test items are presented as words" [2]. Clearly, and evidently presented in many conducted research tests. "The picture superiority effect showed a clear developmental trend" [2]. Designing industrial and commercial buildings poses urban and compositional challenges, especially when the production process implies the use of various technological equipment that can pollute the environment. In general, Kosovo's industrial development was based on the exploitation of raw materials and their processing to a certain degree, but not to a satisfactory degree of processing and finalization. Diversity of design of complex structures must always be in line with the requirements of technological processes, trends, economic development, environmental protection and sustainable human development. The study presented in this paper investigated the visual design guidelines for complex structures, focussing on architectural design issues, aimed primary for education purposes. The research method consists of empirical observation through the Prishtina region zone, with an accent to the

urban shapes, design functionality, visual perception, and compositional harmony as a contemporary reflection to the design system models [3].

\section{MATERIALS AND METHODS}

"It is evident that in visual perception we operate by crucial fundamental principles that make us to group visual system components in some meaningful recognizable forms. These logical criterions are of great importance in the architectural compositions, moreover, this visual grouping is indicative in the wide perceptual range, from the organization of simplest brick wall to the urban composition of metropolitan areas" [3].

"It took me a long time to understand the relationship between ideas and between objective facts. But after I clearly understood this relationship, I didn't fool around with other wild ideas. That is one of the main reasons why I just make my scheme as simple as possible.” 


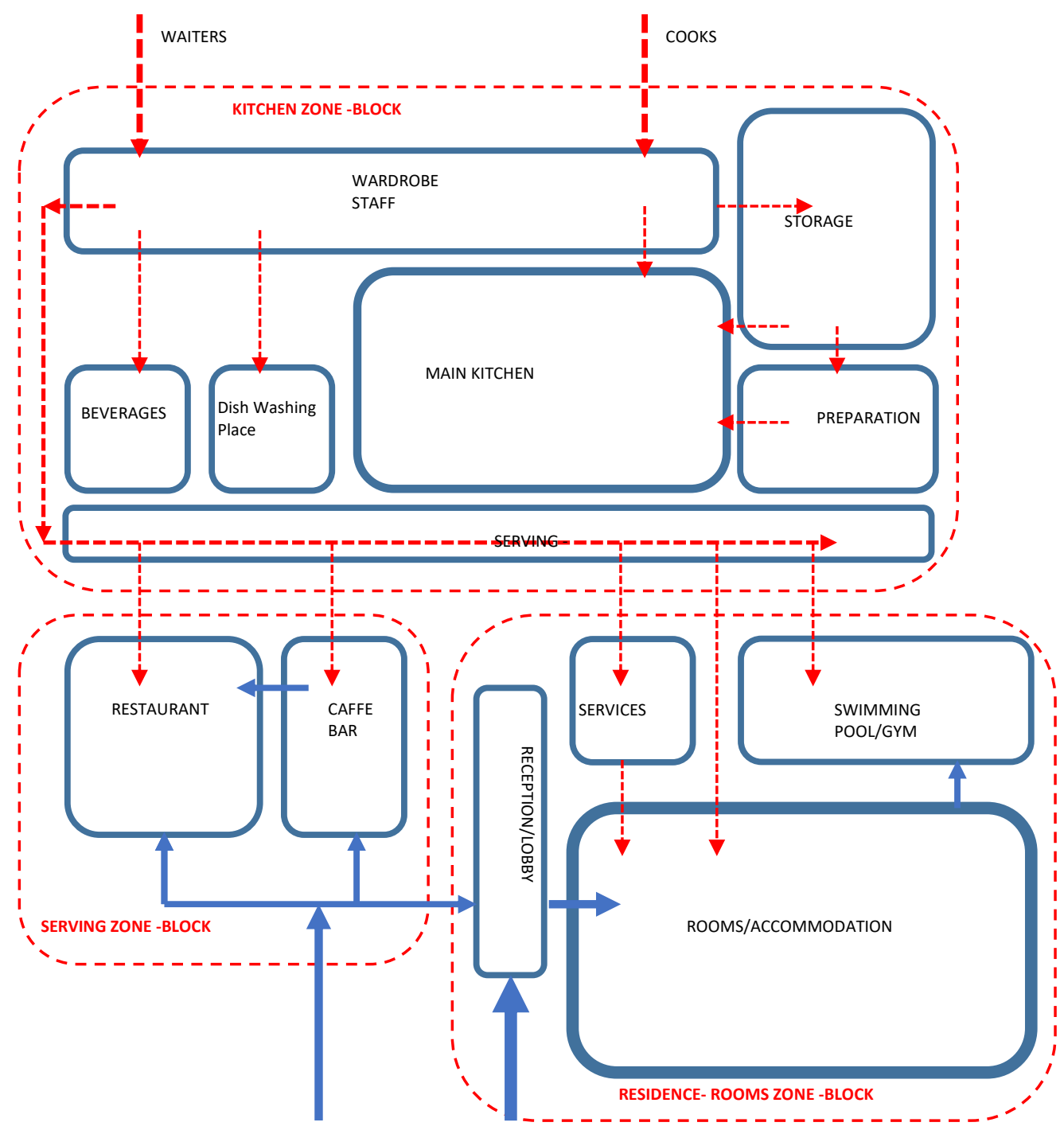

Figure 1. Functional composition zones, design guidelines - Hotel. 


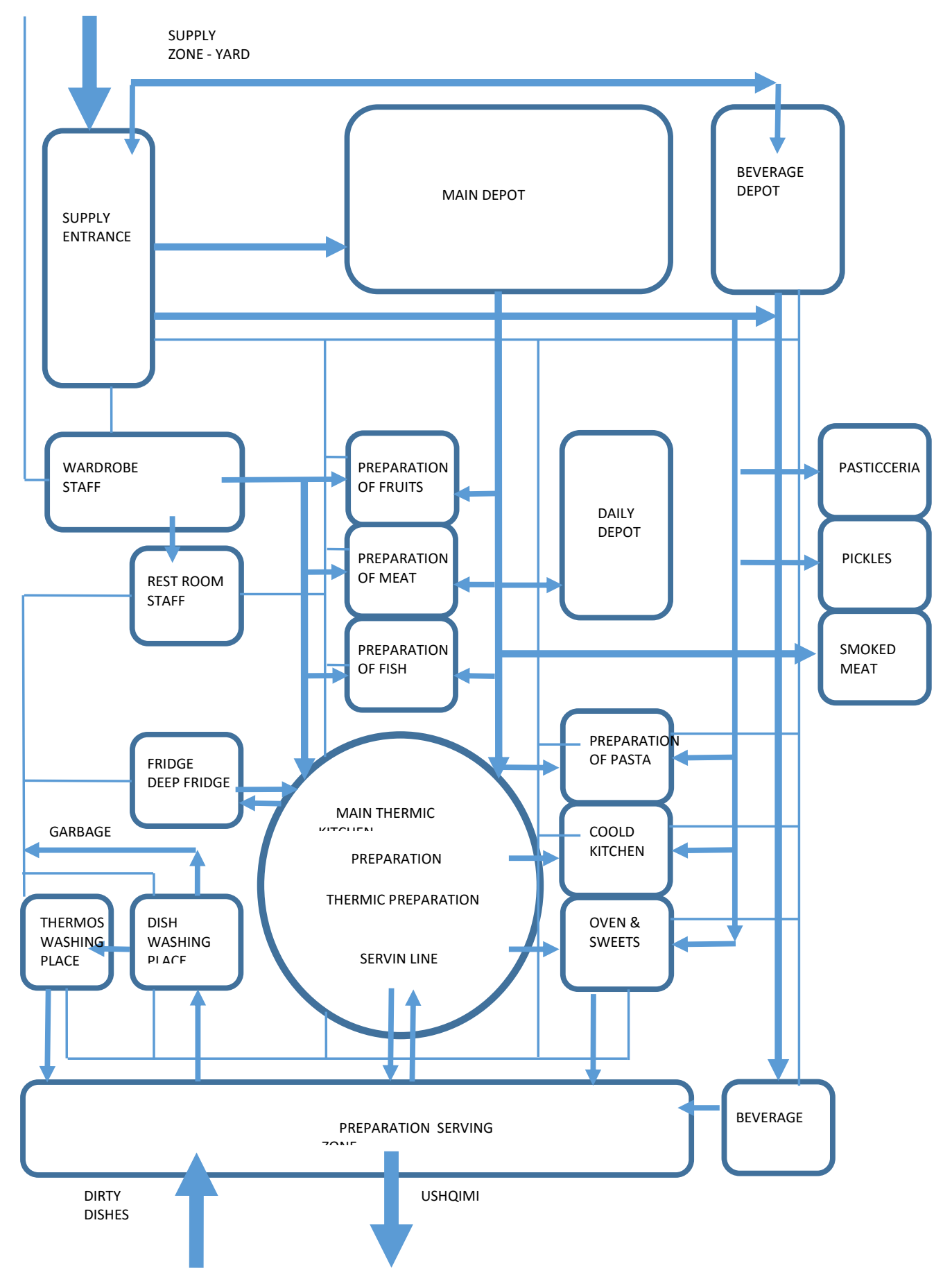

Figure 2. Functional zones, design guidelines-main distributive kitchen - Hotel and Mall. 


\section{JOSHA}

Journal of Science,

Humanities and Arts

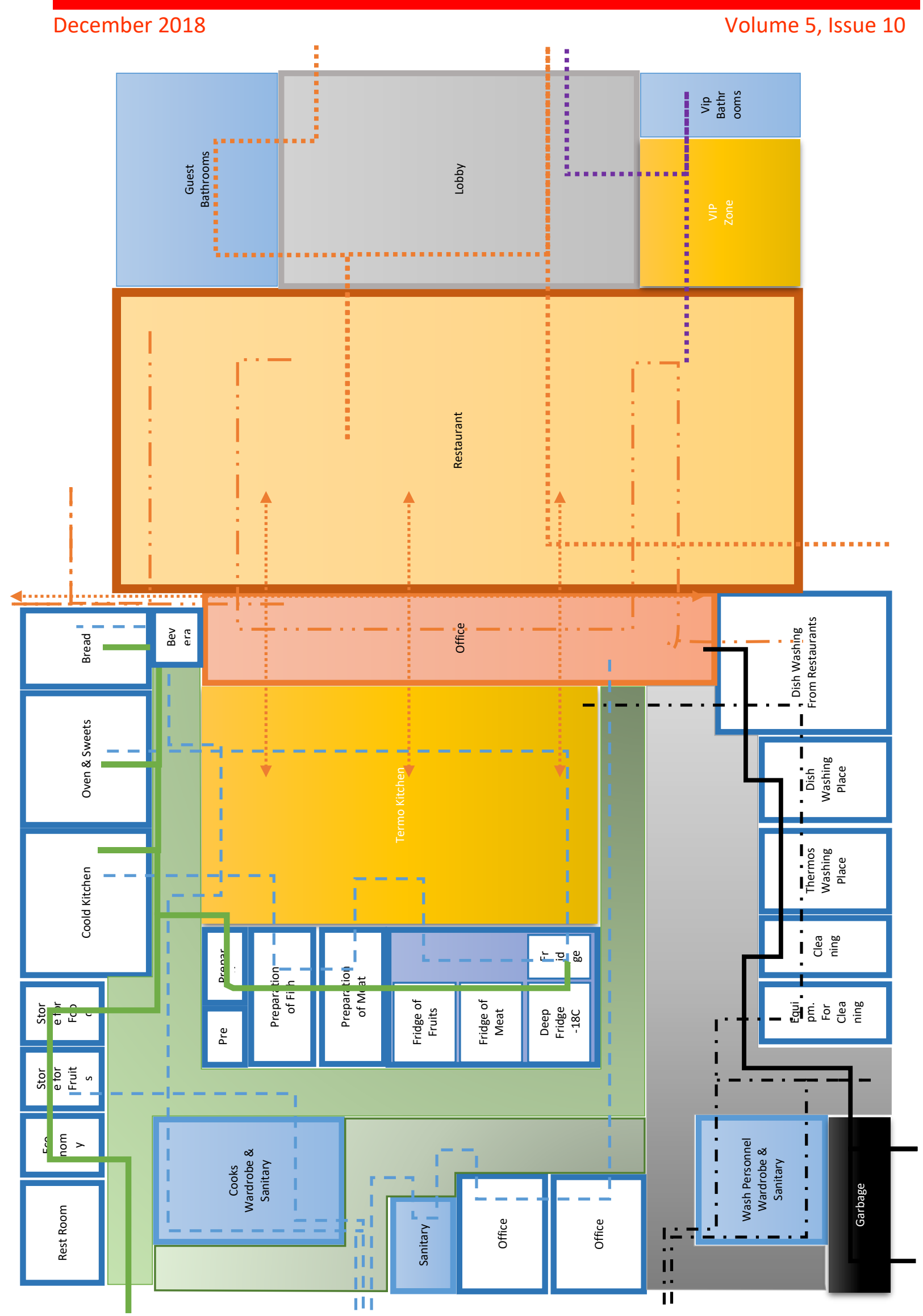

Figure 3. Functional zones, design guidelines - Main Kitchen, Hotel and Mall. 


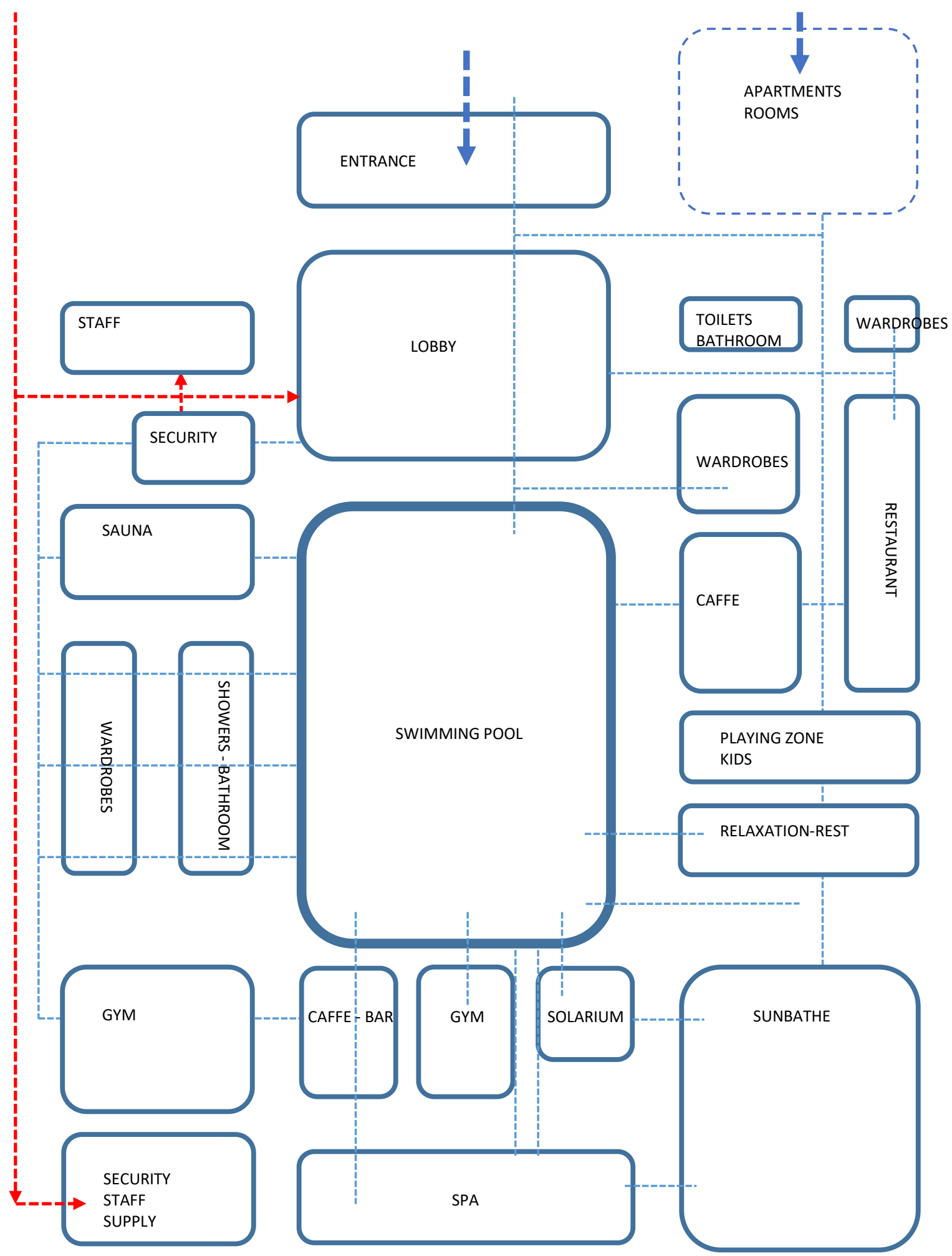

Figure 4. Functional zones, design guidelines-SPA- Swimming Pool, Hotel and Mall. 


\section{JOSHA}

Journal of Science,

Humanities and Arts

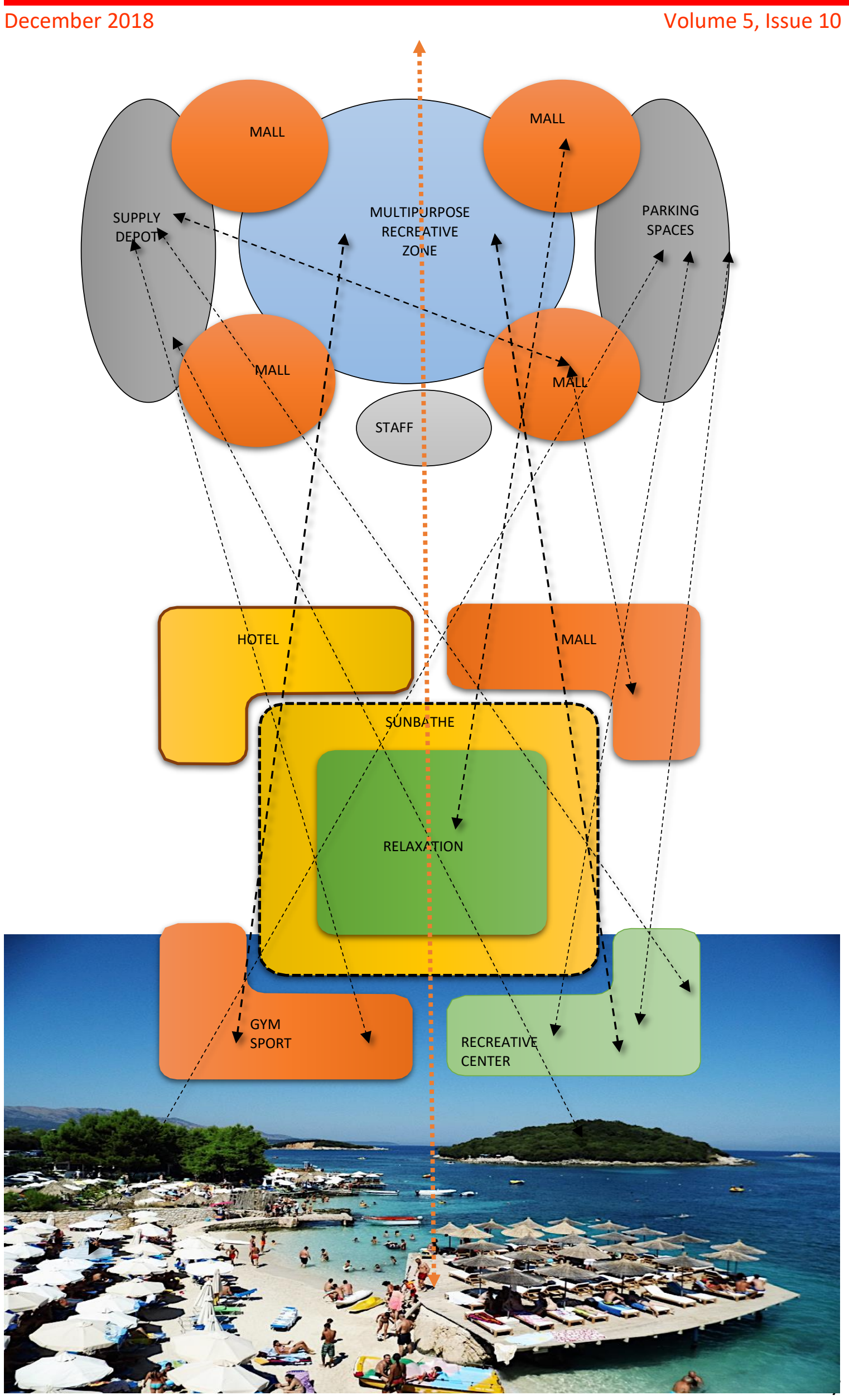


Figure 5. Functional compositional zones, design guidelines. Complex structures.

\section{DISCUSSION}

"General and free access to knowledge is a fundamental principle of science and humanities: only work that can be debated, challenged, tested, verified or reproduced by others qualify as scientific work, anything else is wasted" [4]. This paper is dedicated to the students of Architecture for educational purposes. The design guidelines incorporate contemporary knowledge of the complex architectural structures, in the paper I have reflected my personal professional experience and literature review I have consulted so far. 


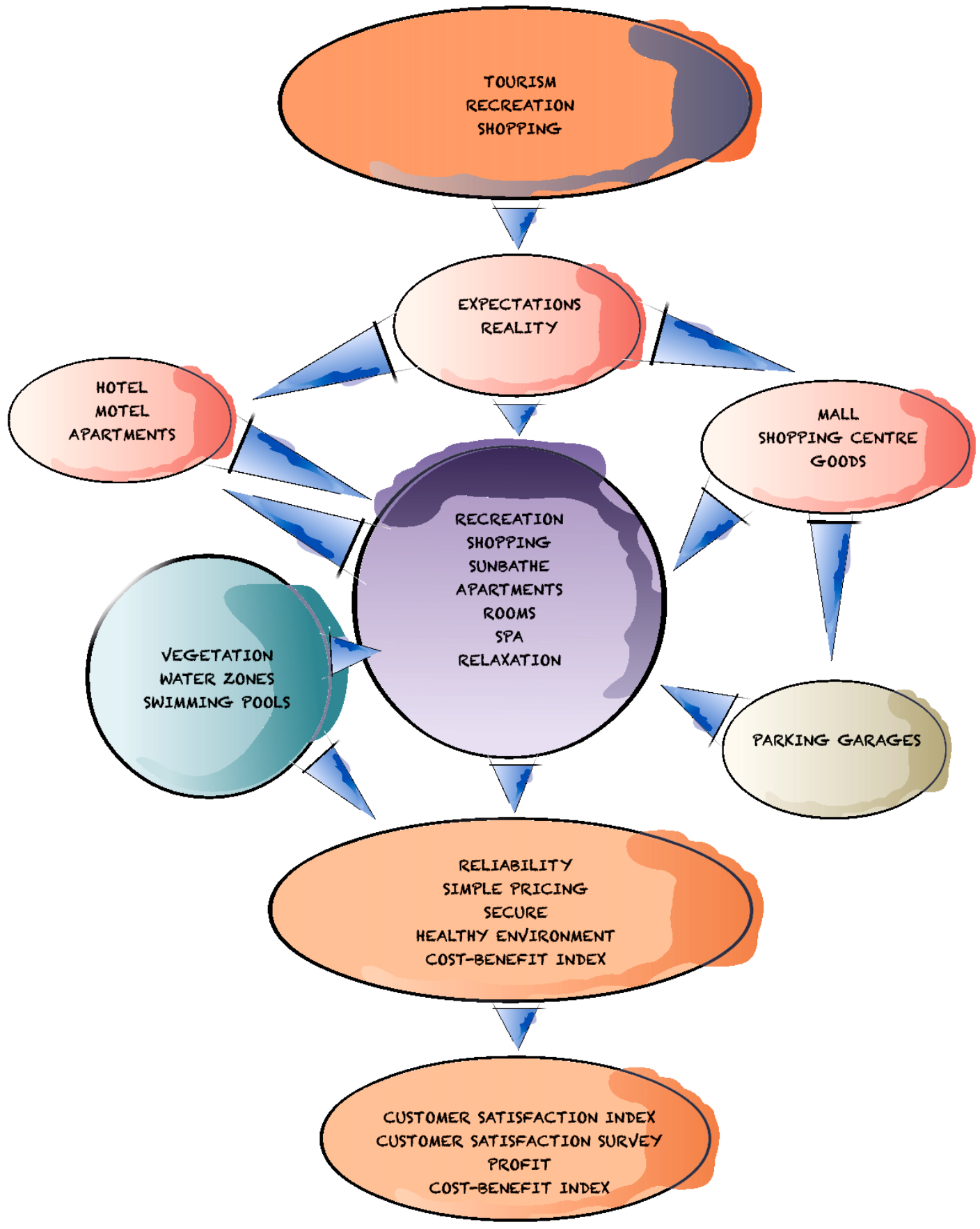

Figure 6. Functional process diagram, design guidelines. Complex structures.

\section{CONCLUSION}

Inadequate solving the specific problems of the time, results in a more vide issues for future generations. Free access to knowledge is a fundamental, furthermore, challenges, associated with the globalization, development of technology, life style, and global world trends are crucial for prosperity. Thus, design subjectivity and response to context, are also of great importance in architectural design expressions when we are considering the best 
possible design solutions. Furthermore, the conceptual instructions from this research, show the need and necessity of adopting the visual design guidelines as the superiority teaching method [3].

\section{REFERENCES:}

[1]. Jeffrey D. Wammes, Melissa E. Meade, and Myra A. Fernandes (2016). The drawing effect: Evidence for reliable and robust memory benefits in free recall. The Quarterly Journal of Experimental Psychology, Vol. 69, No. 9, 1752-1776, http://dx.doi.org/10.1080/17470218.2015.1094494

[2]. Margaret Anne Defeyter, Riccardo Russob, Pamela Louise McPartlin, (2009). The picture superiority effect in recognition memory: A developmental study using the response signal procedure. Cognitive Development 24 (2009) 265-273. Elsevier. doi:10.1016/j.cogdev.2009.05.002

[3]. Bajçinovci, B., Aliu, V. (2018). Visual Organization of Industrial Functional Compositions. JOSHA, Journal of Science, Humanities and Arts. Volume: 5 Issue: 5, Freiburg Germany. DOI: 10.17160/josha.5.5.437

[4]. Gerhard G. Steinmann, Roland Mertelsmann. (2018). Knowledge That is Not Communicated is Wasted: JOSHA - Open Access with Author Copyright. JOSHA, Journal of Science, Humanities and Arts. Volume: 5 Issue: 9, Freiburg Germany. DOI: 10.17160/josha.5.9.488 